\title{
Subordinasi dan objek seksual: Representasi perempuan Bali dalam dua cerpen Indonesia tentang sabung ayam
}

\author{
I Wayan Artika \\ Universitas Pendidikan Ganesha, Singaraja Bali \\ email: batungsel@yahoo.com
}

\begin{abstract}
Abstrak
Artikel ini mengkaji tajen (sabung ayam) dan representasi perempuan Bali dalam dua cerpen, yaitu "Tajen" (Faisal Baraas, 1971) dan "Tajen Terakhir" (Gde Aryantha Soethama, 2016). Topik ini dipilih karena dalam dunia tajen laki-laki direpresentasikan memiliki kuasa mutlak atas perempuan Bali. Untuk itu, dipilih ancangan deskriptif kualitatif, pendekatan intertektualitas, dan metode analisis data membaca paralel. Permasalahan dipecahkan dengan teori new historicism. Data berupa teks sastra bertema tajen dan teks nonsastra tentang tajen. Teks nonsastra sebagai ko-teks, terdiri atas cerita rakyat Bali, catatan perjalanan wisata, lontar pengayam ayam, dan laporan penelitian mengenai tajen. Hasil penelitian menyimpulkan tiga hal. Pertama, dunia tajen yang direpresentasikan dalam kedua cerpen adalah konstelasi dinamis sejumlah aspek, seperti laki-laki/bebotoh, taruhan, ayam jago, dan obsesi kemenangan; Kedua, obsesi kemenangan para bebotoh berada di atas urusan keluarga, istri, anak; Ketiga, perempuan dalam dunia tajen menjadi subordinat dan objek seksual laki-laki/bebotoh. Nasib tragis perempuan dalam dunia tajen terjadi karena praktik ideologi laki-laki.
\end{abstract}

Kata kunci: new historicism, tajen, perempuan Bali, cerpen Indonesia

\begin{abstract}
This article examines tajen (cockfighting) and representation of Balinese women in two short stories, "Tajen" (Faisal Baraas, 1971) and "Tajen Terakhir" (Gde Aryantha Soethama, 2016). This topic was chosen because in the world of tajen men are represented of having the absolute power over Balinese women. Selected descriptive qualitative approach, intertextuality approach, and parallel reading data analysis
\end{abstract}


method. Problem solved with new historicism theory. Data in the form of literary text and nonliterature text about tajen. The nonliterature texts as a co-text, such as Balinese folklore, traveling report, Balinese cockfighting manuscript, and research report about tajen. The results concluded three points. First, the world of tajen represented in both short stories were dynamic constellation of a number of aspects, such as male/gambler, betting, rooster, and victory obsession. Second, the obsession with the victory is above family, wife, and children matters. Third, women in the world of tajen become subordinate and sexual objects of men. The tragic fate of women in the world of tajen occurs because of the practice of patriarchy ideology.

Key words: new historicism, cockfighting, Balinese women, Indonesian short story

\section{Pendahuluan}

Tudi sabung ayam atau tajen sangat populer sekaligus kontroversial dalam masyarakat Bali. Popularitasnya terjadi karena banyak orang yang gemar sabung ayam. Ini menjadi kontroversial karena pemerintah sudah melarang segala bentuk perjudian. Meskipun dilarang, tajen (selanjutnya tidak dicetak miring) masih berlangsung di Bali dan dilaksanakan sembunyi-sembunyi. Bentukjudi ini sangat sulit dihapus. Berita-berita penangkapan dan pembubaran judi sering muncul di media massa, tetapi judi ini tetap berkelanjutan. Meskipun demikian populer dan kontroversial dalam wacana publik, tajen kurang populer sebagai tema karya sastra, jarang diangkat ke dalam karya sastra sebagai tema atau inti cerita. Pada konteks dunia sastra, tajen kurang populer dibandingkan tema konflik kasta, konflik adat, pariwisata, dan ketimpangan gender. Kondisi serupa juga ditemukan dalam dunia penelitian. Jarangnya isu tajen diteliti, dibandingkan dengan isu lain di Bali, pernah disampaikan antropolog Clifford Geertz seperti berikut ini:

Bali, terutama ia adalah Bali, merupakan sebuah tempat studi yang baik. Mitologi, seni, ritus, organisasi sosial, pola-pola pengasuhan anak, bentuk-bentuk hukum, bahkan gaya-gaya trans, semuanya secara mikroskopis telah diteliti untuk mencari isi rumit yang oleh Jane Belo disebut "Perangai orang Bali". Tetapi, lepas dari beberapa pernyataan yang pernah diberikan, sabung-ayam hampir tidak pernah diperhatikan 
[....] (Geertz, 1996:211)

Sementara itu, semesta teks kuno, melahirkan lontar Pengayamayam, teks perjudian (khususnya sabung ayam), menduduki posisi sama terhormat dengan teks literatur tentang perhitungan hari baik seperti wariga, usada (pengobatan), niti (kepemerintahan), pamancangah (sejarah klan), babad (silsilah), lelampahan (lakon), dan lain sebagainya.

Keberadaan tajen di tengah kebudayaan Bali selalu dipersoalkan. Pada satu sisi, ada keiinginan menghapusnya karena bertentangan dengan agama Hindu dan hukum. Oleh karena itu, penolakan mulai santer sejak kemerdekaan (Geertz, 1996; Setia, 1986). Namun demikian, ternyata sangat sulit menghapus tajen (Atmadja, dkk., 2015). Sehubungan dengan sulitnya menghapus tajen, Atmadja dkk. (2015) menggunakan beberapa teori mengenai hakikat manusia untuk memahami permasalahan ini, sehingga masyarakat dan penegak hukum diharapkan memiliki perspektif baru dalam menyikapi keberadaan tajen. Pada sisi lain, keberadaan tajen dipandang sebagai salah satu warisan budaya yang harus dilestarikan. Sehubungan dengan hal ini, tabuh rah ditawarkan sebagai pengganti istilah tajen untuk menetralisasi kesan "judi" (Setia, 2014:122).

Selain kasta, tajen banyak ditulis, hanya saja kurang diteliti dalam konteks masalah judi. Tajen muncul dalam sejumlah teks masa lampau, seperti lontar Pengayam-ayam, cerita rakyat "I Bagus Diarsa", "Men Tuung Kuning", "I Kenengneng", dan "Manik Angkeran". Lontar Pengayam-ayam memuat berbagai ketentuan mengenai spesifikasi ayam aduan, hari baik bersabung ayam berdasarkan perhitungan dalam kalender Bali, dan dauh (waktu) dalam melakukan persabungan. Cerita rakyat, "I Bagus Diarsa" dan "I Kenengneng" merepresentasikan obsesi kemenangan seorang bebotoh (penjudi), tercapai setelah memperoleh anugerah ayam jago Dewa Siwa (dalam cerita "I Bagus Diarsa") dan Betara Guru (dalam cerita "I Kenengneng").

Sementara dalam teks sastra Indonesia, sejak 1970-an hingga pertengahan 2016, tercatat empat pengarang Bali membicarakan tajen baik sebagai latar belakang cerita maupun menjadi persoalan pokok. Para pengarang tersebut, Faisal Baraas (2 judul), Gde Aryantha Soetama, I Wayan Sunarta, dan Ni Komang Ariani 
(masing-masing 1 judul).

Di antara cerpen "tajen" tersebut, “Tajen" (Faisal Baraas, 1971) dan "Tajen Terakhir" (Gde Aryantha Soetama, 2016), menarik dibahas karena membicarakan tajen sebagai pokok permasalahan karya. Selain itu, ditinjau dari segi kedudukan perempuan Bali, kedua cerpen ini memiliki paralelitas dengan cerita rakyat "Tuung Kuning". Tajen dalam cerita "Tuung Kuning" dan cerpen "Tajen" serta "Tajen Terakhir" merupakan bangunan dunia laki-laki yang seolah hendak menegaskan, betapa besarnya kuasa laki-laki Bali atas perempuan. Dalam cerita "Tuung Kuning", nilai anak perempuan ditera setara pakan jago. Sementara dalam "Tajen", seorang istri bisa ditukar uang taruhan. Dalam "Tajen Terakhir", istri yang berzina jauh lebih hina dan tidak terampuni ketimbang suami memotoh (gila judi). Hal ini berkaitan dengan pandangan Geertz (1996:249), “Di dalam sabung-ayam, lantas, orang Bali membentuk dan menemukan wataknya dan sekaligus prangai masyarakatnya" dan tajen sendiri merupakan cara hidup orang Bali (Geertz, 1996:207).

Artikel ini bertujuan untuk mengungkap representasi dunia tajen dalam cerpen Indonesia dengan menjadikan cerpen "Tajen" dan "Tajen Terakhir" sebagai objek kajian. Fokus uraian adalah mengkaji persoalan sosial yang diungkapkan di dalam kedua cerpen yang dilihat dari bagaimana kedudukan perempuan Bali di dalam dunia tajen direpresentasikan kedua cerpen. Kajian cerita tajen secara umum dan dalam konteks representasi gender belum banyak dilakukan peneliti. Salah satu studi tentang ini dilakukan Putra (2011) dalam buku $A$ Literary Mirror Balinese reflections on modernity and identity in the twentieth century. Di sini, Putra membahas identitas perempuan Bali seperti direpresentasikan dalam teks-teks sastrawan Bali dan menjadikan cerpen Faisal Baraas berjudul 'Tajen' sebagai salah satu objek analisis. Putra menunjukkan betapa lemahnya posisi perempuan dalam dunia domestik ketika suaminya seorang penjudi, meski juga akhirnya tokoh laki-laki (suami) dilukiskan sedih melihat istrinya bunuh diri, sebuah kesedihan yang terlambat (Bab IV, 2011:187-225). 


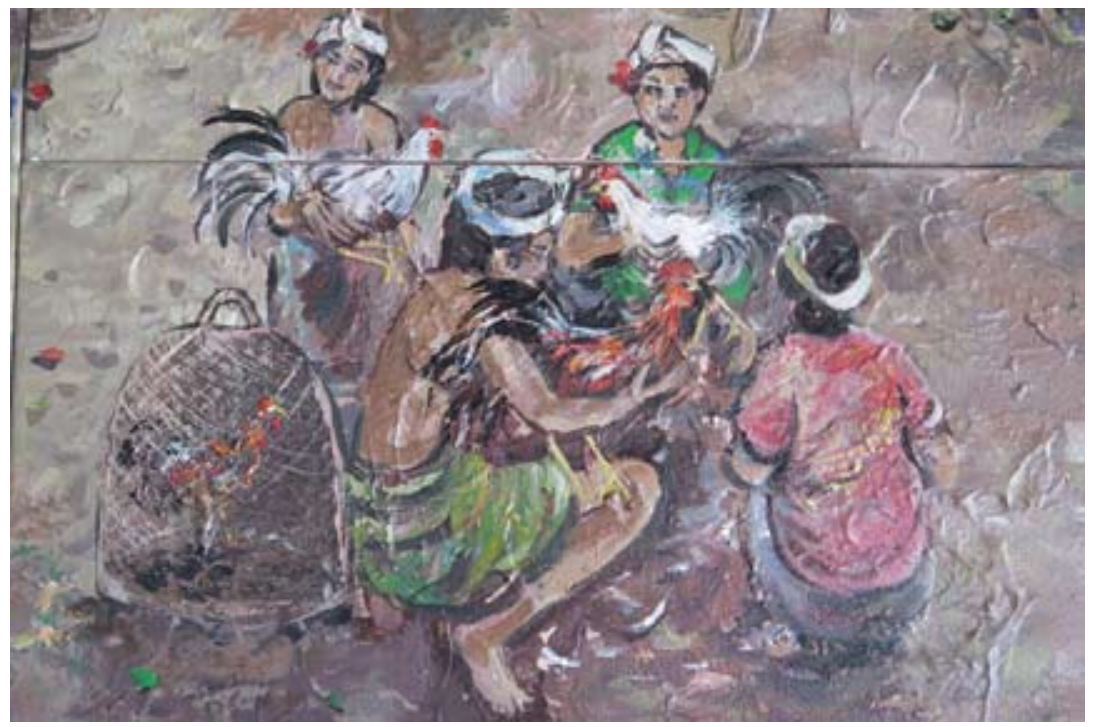

Foto. Gambaran tajen di Bali dalam sebuah lukisan.

\section{New Historicsm dan pembacaan paralel}

Untuk mencapai tujuan tersebut, permasalahan artikel ini dipecahkan dengan teori new historicism dan metode analisis data membaca paralel. Istilah new historicism diperkenalkan oleh kritikus Amerika, Stephen Greenblatt (Greenblatt, 2005:18). New historicism muncul pada tahun 1971 dalam sejumlah studi yang mengaitkan drama-drama Jacob dengan peristiwa politik zamannya (Barry, 2010:201). Menurut Selden dan Widdowson (1993:163), new historicism dipengaruhi oleh Michel Foucault dan Louis Althusser. Menurut Foucault dan Althusser, pengalaman manusia dibentuk oleh lembaga sosial, khususnya wacana ideologi.

New historicism menawarkan sudut pandang baru dalam kajian sastra yaitu menganalisis hubungan karya sastra dan berbagai kekuatan sosial, ekonomi, dan politik yang melingkupinya (Brannigan, 1999:421; Bressler, 1999:236; Barry, 2010:201; Budianta, 2006:2-3). Hubungan tersebut terjadi karena karya sastra, antropologi, dan sejarah adalah fiksi dalam pengertian sebagai teks yang diciptakan dan dibentuk oleh imajinasi, dengan memanfaatkan sumber-sumber yang tersedia (Grennblat, 2005:37). Menurut pandangan postmodern, sejarah dikonstruksi oleh imajinasi sastra dan relasi kekuasaan sehingga ideologis dan subjektif (Liu, 2006:2). Sementara itu, sastra adalah visi lain tentang sejarah dan sejarah 
tidak dapat dimengerti sepenuhnya secara objektif (Greenblatt, 1980:3-6).

New historicism memandang sejarah sastra bagian sejarah kebudayaan besar. Sejalan dengan ini, dapat dirumuskan, tajen merupakan bagian dari dinamika kebudayaan Bali. Hal ini menjadi landasan berpikir mengkaji cerpen "Tajen" dan "Tajen Terakhir" yang diparalelkan dengan teks nonsastra mengenai tajen, yang merupakan konteks sosial, politik, dan sejarah kebudayaan, sebagaimana pendapat Selden dan Widdowson (1993:161). Mengacu kepada Greenblatt (1980:3-6), Kedua cerpen memiliki basis sejarah, dalam kaitan ini sejarah Bali dan produk proses sejarah serta kebudayaan Bali. Bersandar pada Culler (1997:130), kedua cerpen ditempatkan di tengah hubungan berbagai lembaga sosial, seperti adat dan ideologi patriarkhi atau purusa. Bersandar kepada Tillyard (dalam Selden dan Widdowson, 1993:162), terdapat interkoneksiantara kedua cerpen dan kebudayaan Bali. Interkoneksi ini ditelusuri lewat paralelitas cerpen dan teks nonsastra.

Menurut Greenblatt (2005:13), makna sebuah teks harus melalui konstruksi situasi zaman yang memproduksi teks bersangkutan. Sejalan dengan pendapat ini, makna kedua cerpen dikaji melalui konstruksi dinamika wacana tajen dalam berbagai teks karena di luar jaringan wacana tajen kedua cerpen tidak bermakna.

Artikel ini menggunakan ancangan kualitatif karena relevan dengan sifat dasar kajian sastra, yaitu interpretatif. Menurut dua pendekatan dalam ilmu sosial (positivism dan interpretative social science), kategori interpetatif mengandung dua konsep, yaitu konstruksi sosial dan menemukan makna (Silverman, 1994:21). Melalui ancangan kualitatif-interpretatif, penelitian ini mengungkap makna kedua cerpen.

Sejalan dengan ancangan yang digunakan, artikel ini ini mendeskripsikan tiga pokok persoalan. Pertama, representasi dunia tajen dalam cerpen "Tajen" dan "Tajen Terakhir". Kedua, muatan persoalan sosial dalam kedua cerpen. Ketiga, kedudukan perempuan Bali dalam dunia tajen yang merupakan salah satu arena kultural bagi laki-laki Bali dalam menjalankan praktik kuasa atas perempuan di bawah naungan ideologi patriarkhi.

Artikel ini menggunakan pendekatan sosiologis, mengingat kedua cerpen terintegrasi dengan proses sosial dan budaya yang 
melahirkan, yaitu kebudayaan Bali. Jenis data penelitian, dokumen karya sastra dan teks nonsastra. Objek material berupa cerpen ("Tajen", Faisal Baraas, 1971 dan "Tajen Terakhir" Gde Aryantha Soetama, 2016), Lontar Pengayam-ayam, cerita rakyat ("I Bagus Diarsa", "Men Tuung Kuning", "I Kenengneng", dan "Manik Angkeran"), laporan perjalanan wisata ("Penyakit Gurun Teko", [Setia, 1986]), dan hasil penelitian Geertz (1996), "Sabung Ayam di Bali".

Data penelitian dikumpulkan dengan metode pustaka. Analisis data menggunakan metode membaca paralel, melakukan aktivitas pembacaan sejumlah teks mengenai tajen secara berdampingan. Metode ini didasari hipotesis, teks yang dibaca berhubungan dengan teks lain dan sebaliknya. Titik fokus pembacaan adalah dunia tajen dan eksistensi perempuan dalam dunia tajen.

Langkah analisis data meliputi tahap sebagai berikut. Pertama, mengkonstruksi ko-teks wacana tajen, dari sejumlah teks, seperti Lontar Pengayam-ayam, cerita rakyat ("I Bagus Diarsa". "Men Tuung Kuning", dan "I Kenengneng"), laporan perjalanan wisata ("Penyakit Gurun Teko"), dan hasil penelitian ("Sabung Ayam di Bali"). Kedua, mengkaji hubungan timbal balik atau paralelitas kedua cerpen tajen dan ko-teksnya. Ketiga, mengungkap makna kedua cerpen.

\section{Konstruksi dunia Tajen: Obsesi kemenangan}

Meskipun Lontar Pengayam-ayam berbicara mengenai dua sisi tajen: menang dan kalah, namun lontar ini disikapi hanya dari sisi kemenangan oleh para bebotoh (sebutan laki-laki Bali penjudi) karena "Bebotoh selalu berobsesi meraih kemenangan" (Atmadja, dkk.2015:109). Harapan ini juga muncul di dalam cerita rakyat bertema tajen, "I Bagus Diarsa", "I Kenengneng", dan "Manik Angkeran" hingga Gurun Teko (dalam "Penyakit Gurun Teko" Setia, 1986). Demikian pula dalam cerpen "Tajen" dan "Tajen Terakhir". Karena obsesi kemenangan itulah, Gurun Teko selalu memburu tajen. Demikian pula laki-laki dalam "Tajen" dan "Tajen Terakhir". Demi obsesi tersebut, mereka tidak peduli dengan setiap kekalahan di arena tajen, walaupun harus menjadi jatuh miskin. Demi obsesi kemenangan itu pula, ia (dalam cerpen "Tajen") menukar istrinya dengan uang taruhan hingga pada akhirnya istrinya bunuh diri. Meskipun seorang bebotoh mengambil keputusan berhenti berjudi 
tajen sebagaimana diungkap dalam cerpen "Tajen Terakhir", ia masih ingin mengejar obsesi kemenangan terakhir. Hal ini menunjukkan, obsesi kemangan itu menguasai kaum bebotoh.

Bagus Diarsa digambarkan sebagai bebotoh berjiwa mulia. Ketika arena sabungan ayam tiba-tiba dilanda bau busuk yang bersumber dari lelaki tua, hadir secara tiba-tiba; ia mengajak makan semeja dan membayar makanan dari uang sisa kekalahan pada hari itu; sementara orang lain tutup hidung dan menjauh. Pengorbanan Bagus Diarsa tidak hanya sampai di sana karena merelakan anak laki-laki satu-satunya dibawa serta oleh lelaki tua (yang sebenarnya Dewa Siwa) ke sorga dan pada waktunya kembali sebagai manusia mulia. Ketika raja menggelar tajen besar Bagus Diarsa tiba-tiba ingat pesan Dewa Siwa--kapan saja bisa mengunjungi anaknya di sorga--dan anugerah bulu ayam pemandu arah menuju sorga. Dalam kesempatan ini, Bagus Diarsa ingin memohon ayam aduan Dewa Siwa untuk melawan ayam raja, demi mewujudkan obsesi kemenangan. Bagi Bagus Diarsa, obsesi ini lebih penting ketimbang kerinduan kepada anaknya. Dewa Siwa menganugrahi sekor jago tidak terkalahkan. Ketika sabungan ayam kerajaan digelar, ayam Bagus Diarsa unggul. Ia memperoleh kemenangan dan kekayaan. Dalam cerita ini, obsesi kemenangan menjadi kenyataan.

Versi lain cerita tersebut, muncul dalam cerita "I Kenengneng", seorang yatim piatu, pergi ke sorga menghadap Batara Guru, menjumpai kedua orang tuanya yang telah meninggal dunia, melalui pohon padi menjulang ke langit. Dari pohon ini sorga terlihat dekat. Hanya dalam satu lompatan ia mencapai sorga. Semula I Kenengneng menginginkan juuk linglang (jeruk umur panjang) milik Batara Guru. Karena keinginan itu tidak terkabul, sebagai gantinya, ia memperoleh anugerah ayam aduan yang tidak terkalahkan. Seperti Bagus Diarsa, I Kenengneng pun menang dalam sabungan ayam melawan raja. Dalam cerita ini kemenangan mutlak seorang bebotoh tidak hanya sekadar obsesi. Kedua cerita ini didasari oleh hakikat tajen, yakni obsesi kemenangan. Obsesi terhadap kemenangan membuat Gurun Teko selalu memburu sabungan ayam di bawah ketakutan akan ancaman penangkapan polisi (Setia, 1986).

"Manik Angkeran" juga paralel dengan cerita "I Bagus Diarsa" dan "I Kenengneng". Manik Angkeran juga memperoleh kemenangan. Setelah itu, ia berhenti berjudi. Bagian cerita ini, 
paralel dengan cerpen "Tajen Terakhir" (Gde Aryantha Soethama, 2016), seorang bebotoh berhenti berjudi setelah meraih kemenangan mutlak ketika tajen terakhir.

Wacana tajen cerita rakyat "Men Tuung Kuning" berbeda jika disandingkan dengan obsesi kemenangn dalam lontar Pengayamayam, cerita "I Bagus Diarsa", "I Kenengneng", dan "Manik Angkeran", laporan perjalanan wisata "Penyakit Gurun Teko", cerpen "Tajen", dan "Tajen Terakhir". Cerita "Tuung Kuning" tidak menyinggung obsesi kememangan bebotoh tetapi ketidakberdayaan perempuan Bali di bawah kuasa dan cinta laki-laki (suami, seorang bebotoh). Harkat perempuan lebih rendah ketimbang lakilaki bebotoh. Laki-laki penjudi masih lebih terhormat daripada perempuan. Ironisnya, dari tubuh perempuan yang dipandang lebih rendah, diharapkan lahir anak laki-laki. Harkatnya semakin rendah jika tidak melahirkan anak laki-laki, lebih rendah lagi jika tidak bisa memberi keturunan, sebagaimana diceritakan dalam cerpen "Tajen".

Men Tuung Kuning menjalani persalinan seorang diri di bawah ancaman suami yang tidak menginginkan bayi perempuan. Dalam dunia tajen harkat perempuan lebih rendah daripada ayam jago (Gerrtz, 1996). Itulah alasan bagi suami Men Tuung Kuning menuntut istrinya: harus melahirkan anak laki-laki dan membunuh bayi perempuan yang dilahirkan untuk makanan jago. Dalam cerita ini kritik terhadap praktik kuasa kaum laki-laki, sangat jelas namun dibaca secara terbalik, justru untuk mengukuhkan atau melegitimasi kuasa patriarkhi atas perempuan Bali. Cerita ini diterima sebagai kebenaran kultural.

Geertz (1996:212) mengkaji aspek-aspek tajen, seperti jago, pertarungan, taruhan, dan sebagai permainan bagi laki-laki. Sabung yang telah muncul dalam prasasti berangka tahun 922 Masehi, sama dengan jago yang berarti "pahlawan", "jejaka", dan "pembunuh perempuan". Menurut Geertz (1996:212), jago tidak hanya berkaitan dengan simbol kekuatan laki-laki; jago juga digunakan untuk mengungkapkan sindiran kepada lakilaki yang angkuh atau sombong, laki-laki yang nekat melakukan usaha penghabisan namun irrasional, laki-laki yang kikir, laki-laki yang sudah waktunya menikah tetapi malu terhadap perempuan. Jago atau sabung, metafora untuk laki-laki. Ayam jago merupakan kesayangan laki-laki Bali (Geertz, 1996:213). Jago sebagai pengganti 
kepribadian pemilik (Geertz, 1996:231).

Atmadja, dkk. (2015:101) menguatkan pandangan Geertz (1996). Menurut Atmadja dkk. (2015:101), ayam aduan (jago) simbol ideologi patriarkhi. Lebih lanjut, Atmadja dkk. mengemukakan:

Hal ini berdasarkan pada asas asosiatif, yakni ayam aduan adalah ayam jantan berasosiasi dengan laki-laki atau maskulinitas. Aspek kejantanan sangat didambakan pada masyarakat Bali yang berbudaya patriarkhi.

Ayam aduan berubah menjadi subjek sehingga tidak sekadar hewan peliharaan tetapi representasi kekuasaan suami terhadap istri dan anak-anaknya (Atmadja, dkk. 2015:102), sebagaimana diceritakan dalam "Men Tuung Kuning".

Berdasarkan uraian di atas, dinamika wacana tajen dalam kebudayaan Bali dapat diidentifikasi menjadi tiga: (1) konstruksi dunia laki-laki Bali sebagai arena kultural mempraktikkan kuasanya atas perempuan, (2) roh tajen adalah obsesi kemenangan, dan (3) wacana untuk menegaskan posisi hierakhis laki-laki dan perempuan.

\section{Perempuan Bali dalam dunia Tajen}

Di antara sejumlah teks tajen yang dibicarakan dalam artikel ini, ada satu cerita yang membicarakan kedudukan perempuan, yaitu cerita "Tuung Kuning". Cerita ini paralel dengan teks yang lebih modern, teks yang lahir dalam wacana global mengenai kesetaraan gender, yaitu cerpen "Tajen" dan "Tajen Terakhir".

Men Tuung Kuning sebagai istri bebotoh, dituntut melahirkan anak laki-laki. Ia berjuang sendiri dalam persalinan ketika suami berjudi. Di bawah tekanan suami Men Tuung Kuning berusaha menyelamatkan anak perempuannya (Ni Luh Tuung Kuning) namun pada ujungnya gagal karena ideologi patriarkhi (purusa) mengalahkan dirinya. Sekembali dari arena tajen, suaminya membunuh anak gadisnya. Namun gagal karena anaknya diselamatkan oleh bidadari.

Persoalan perempuan dalam cerpen "Tajen" paralel dengan persoalan yang dialami Men Tuung Kuning. Dalam cerpen ini, terungkap kehidupan seorang istri bebotoh (penjudi tajen) yang tidak bisa memberi keturunan. Ia dipandang rendah oleh laki-laki dan hanya pantas ditukar dengan uang taruhan ("Tajen", Faisal Baraas, 1971). Cerpen ini menonjolkan dunia bebotoh yang hanya 
memburu obsesi kemenangan dan kesenangan:

Lelaki itu menjual seluruh sawahnya untuk mencari ayam yang totosan. Ia berkeliling ke seluruh desa-desa di Bali. Tapi setiap kali ayam jagonya berhadapan dengan si hijau milik Gus Gria, si hijau itu selalu menang. Dan lelaki itu tidak pernah bisa menaklukkan Gus Gria di gelanggang tajen. Di mana saja. (“Tajen”, hlm.32)

Kutipan tersebut merepresentasikan posisi subordinat perempuan Bali dalam dunia tajen, dunia laki-laki atau permainan yang digemari laki-laki Bali (Geertz, 1996). Kehidupan perempuan dalam cerpen "Tajen" dipandang berada di bawah urusan laki-laki yang sehari-harinya hidup berjudi.

Sementara itu, istri dalam "Tajen Terakhir" (Gde Aryantha Soetama, 2016), mengungkap dua pandangan: perempuan sumber tabu dan objek seksual:

[...] Kini ia sadar, perempuan yang berbulan-bulan tidak ia jamah demi melaksanakan perintah lontar Pengayam Pegat agar sampai ke tajen terakhir, adalah wanita sintal dengan pinggul padat [...] ("Tajen Terakhir", hlm. 31)

Sebagai salah satu praktik ideologi patriarkhi, persoalan tabu seksual yang melekat pada tubuh perempuan dikonstruksi oleh kuasa laki-laki. Karena konstruksi itu, laki-laki Bali tidak dipandang memiliki potensi sumber tabu. Ketika mengalami datang bulan perempuan dipandang mengotori kesucian laki-laki dan pura. Dalam kehidupan sehari-hari, perempuan Bali yang sedang mengalami datang bulan tidak diizinkan masuk pura atau tempat suci lainnya dan tidak dilibatkan dalam kegiatan upacara di pura. Dalam cerpen "Tajen Terakhir" konstruksi pandangan perempuan sebagai sumber tabu, juga ditemukan. Seorang suami yang sedang mempraktikkan ajaran suci dalam lontar Pengayam pegat, pantang melakukan hubungan seksual.

Cerita "Tuung Kuning" mengkonstruksi perempuan Bali sebagai objek kultural yang menerima nasib tragis. Dalam cerpen "Tajen" dan "Tajen Terakhir" perempuan Bali menjadi objek seksual laki-laki, sebagai konsekuensi kedudukan perempuan yang lebih rendah daripada laki-laki. Dalam cerpen "Tajen" kuasa lakilaki atas perempuan dikemukakan secara eksplisit: (1) istri yang tidak mampu memberi keturunan dipandang rendah sehingga (2) 
seorang suami bisa menukar istrinya sendiri dengan uang taruhan. Dalam hal ini, cinta seorang istri tunduk di bawah kuasa suami.

Cerita "Tuung Kuning", cerpen "Tajen", dan "Tajen Terakhir" menggambarkan suatu bangunan dunia kuasa laki-laki, yang mana di dalamnya perempuan menduduki posisi sangat rendah. Walaupun cerita "Tuung Kuning" dibaca secara kultural untuk melegitimasi kuasa laki-laki Bali, namun ide kesetaraan gender telah ada di masa lampau. Untuk mengubah makna sosial cerita "Tuung Kuning" serta untuk lebih menguatkan pesan adanya ketertindasan perempuan Bali, diperlukan cara pembacaan baru. Lewat pendekatan intertekstualitas dan metode pembacaan paralel, new historicism dalam artikel ini, memberi sumbangan berupa cara pembacaan baru terhadap ketiga teks tajen tersebut.

\section{Persoalan sosial dalam cerpen "Tajen" dan "Tajen Terakhir"}

Persoalan sosial dalam cerpen "Tajen" obsesi terhadap kemenangan yang ibarat candu bagi kaum bebotoh. Kekalahan demi kekalahan, berakibat kemiskinan, tidak mampu mengakhiri atau melepaskan diri dari pengaruh candu tajen. Sebaliknya, seorang bebotoh berusaha mencari segala cara untuk memperoleh uang taruhan, mengejar obsesi kemenangan, dan menikmati candu tajen, hingga jalan terakhir yang tidak masuk akal, "mempertaruhkan" istri, menukar istri dengan uang:

Dan tajen yang terakhir di Desa Kesiman itu sangat menggoncangkan perasaannya. Apalagi yang harus dijualnya untuk bisa mengunjungi tajen itu? Ia tidak punya apa-apa lagi. Dan satu-satunya yang tinggal hanyalah rumahnya, Dan istrinya yang cantik. (“Tajen”, hlm. 31)

Obsesi kemenangan telah digambarkan dalam teks-teks tajen kuno, seperti "Bagus Diarsa", "I Kenengneng", dan "Manik Angkeran". Setiap bebotoh memiliki obsesi kemenangan, menjadi resepsi paling umum atas pembacaan Pengayam-ayam, hanya pada satu sisi: kemenangan padahal lontar ini memaparkan juga sisi kekalahan.

Persoalan sosial dalam "Tajen Terakhir" lebih satiris karena mustahil seorang bebotoh sanggup keluar dari candu sabung ayam. Cerpen ini menggambarkan pergulatan bebotoh agar bebas dari obsesi kemenangan. Berkat nasihat temannya agar membaca lontar Pengayam pegat, ia memperoleh kemenangan terakhir, namun tidak 
ada artinya ketika berhadapan dengan kenyataan: istrinya berzina dengan sahabatnya sendiri pada saat ia berada di arena tajen terakhir. Dalam cerpen ini, obsesi kemenangan terakhir sekaligus sebagai jalan untuk berhenti berjudi, tidak menjadi fokus cerita. Hal ini hanya berfungsi struktural untuk menuju fokus lain cerita, yaitu seorang istri berzina dan tertangkap basah. Tegangan cerpen "Tajen Terakhir" akhirnya tidak terletak pada keberhasilan seorang bebotoh melepaskan diri dari obsesi kemenangan, tetapi pada seorang istri yang tertangkap basah saat berzina. Lewat teknik ini pengarang menunjukkan sikap bahwa tidak mudah bagi seorang bebotoh melepaskan diri dari obsesi kemenangan.

Obsesi kemenangan, ancaman keterpurukan hidup, keinginan berhenti menjadi bebotoh, namun tidak mudah diwujudkan dalam tindakan, menjadi permasalahan klasik dalam tajen dan judi pada umumnya. Obsesi kemenangan tergambar jelas dalam "Tajen", seperti pengalaman IBagus Diarsa, I Kenengneng, Manik Angkeran, dan Gurun Teko. Obsesi kemenangan mengantarkan I Bagus Diarsa ke surga, bertemu Dewa Siwa memohon ayam aduan; I Kenengneng memperoleh ayam Batara Guru; memberi keberanian kepada Gurun Teko untuk selalu hadir di arena sabungan ayam walaupun di bawah ancaman penggerebekan polisi. Obsesi ini mengalahkan cinta, sikap hormat seorang suami kepada perempuan (istri) yang dinikahinya.

\section{Perempuan Bali dalam dunia Tajen}

Teks tajen yang lebih kuno (cerita rakyat dan lontar Pengayam ayam) hanya membicarakan obsesi kemenangan dengan mengecualikan cerita "Tuung Kuning". Cerita ini digunakan membicarakan posisi perempuan dalam masyarakat Bali yang menganut ideologi patriarkhi. Dalam kedua cerpen "Tajen" dan "Tajen Terakhir", selain obsesi kemenangan juga mengungkapkan cinta dan nasib tragis istri di bawah kuasa suami.

Representasi nasib tragis perempuan dalam cerpen "Tajen" paralel dengan nasib tragis perempuan Bali dalam cerita "Tuung Kuning". Men Tuung Kuning tidak berdaya di bawah kekuasaan seorang bebotoh. Ia menjalani persalinan sendiri, sementara suami bersenang-senang di arena tajen. Men Tuung Kuning terancam pesan suami, yang tidak menginginkan anak perempuan karena anak laki-laki lebih tinggi nilainya ketimbang anak perempuan. 
Nilai anak perempuan hanya setara pakan jago. Nasib tragis Men Tuung Kuning dan perempuan dalam kedua cerpen, dapat dipahami melalui praktik ideologi patriarkhi dan dengan menggunakan konsep baru, yaitu status kebinatangan, kanibalisme, pemujaan kuasa roh-roh yang minta dipuaskan korban darah segar (Geertz, 1996:215).

Perempuan dalam cerpen "Tajen Terakhir" tidak setragis Men Tuung Kuning atau perempuan dalam "Tajen". Perempuan "Tajen Terakhir" menjalani perzinaan. Cerpen ini menunjukkan perlawanan diam-diam perempuan atas kuasa laki-laki, melalui praktik zina. Namun demikian, pengarang tetap mengunggulkan kuasa laki-laki. Istri yang sedang bermain asmara tertangkap basah oleh suaminya. Dalam hal ini, nasib atau hukuman yang diterima istri sebagai ganjaran perbuatan zina itu, pada akhirnya ditentukan oleh kuasa laki-laki.

Nasib perempuan dalam "Tajen" amat tragis. Kekalahan demi kekalahan suami dan obsesi kemenangan sampai pada tindakan "menukar" istrinya demi uang taruhan sehingga ia bisa berjudi lagi. Dalam hal ini, harga seorang istri setara nilai taruhan. Kutipan di bawah ini menggambarkan Gus Gria yang baru saja usai meniduri istri temannya yang ia tukar dengan sejumlah uang taruhan:

Hatinya berdebar-debar dan pikirannya kosong.

"Alangkah sepinya," bisiknya lirih.

Tiba-tiba pintu rumahnya dibuka. Dengan tergesa-gesa tampak Gus Gria keluar dan rambutnya awut-awutan. Mereka berhadapan sejenak. Gus Gria hanya menatapi lelaki itu dan mencoba berbicara.

"Ia di dalam," suaranya serak

(“Tajen”, hlm. 32-33)

Untuk mengakhiri hidup, istri gantung diri.

Tubuh wanita itu terhempas ke bawah, diiringi suara nafas yang terhentak. Begitu cepatnya hal itu terjadi dan begitu tenangnya.

Lelaki itu masih tertegun. Bagaikan patung yang tertancap di tempatnya. Ia seperti mimpi menyaksikan apa yang telah diperbuat istrinya. Ia memandangi tubuh wanita itu, yang kian terjuntai-juntai di tiang gantungan.

("Tajen", hlm. 33)

Sikap Faisal Baraas terhadap nasib perempuan dalam "Tajen" jelas: bunuh diri. Tapi hal itu tidak tampak dalam sikap Gde 
Aryantha Soethama. Nasib perempuan tidak jelas: diampuni atau ditebas arit, seperti dikutip di bawah ini.

Nyoman Pongkod menatap tengkuk istrinya yang mulus, jelas berkilat karena rambut tergerai tersibak. Sekujur tubuh Pongkod gemetar hebat, dadanya sesak. Perempuan yang ia cintai menunduk beku menunggu keputusan, siap menerima segala tiba.

("Tajen Terakhir", hlm. 21)

"Siap menerima segala tiba" dalam "Tajen Terakhir" mencerminkan kuasa laki-laki atas istri. Apapun keputusannya (dibunuh atau diampuni) itu menunjukkan kuasa laki-laki atas perempuan.

Yang menarik, kedua cerpen merepresentasikan perempuan berparas cantik, menimbulkan godaan laki-laki lain. Salah satu pandangan kuasa laki-laki di bawah patriarkhi atau purusa, perempuan menjadi objek seksual. Hal ini dikaitkan dengan keindahan atau kecantikan yang mengundang gairah seksual laki-laki. Dalam cerpen "Tajen" perempuan sebagai objek seksual seperti dalam kutipan:

[...] Gus Gria telah lama menginginkan istrinya. Ia tergila-gila pada istri lelaki itu.

[...] ijinkan saya tidur dengan istrimu sehari saja. Bukankah hal itu tidak apa-apa?[...]"

(“Tajen", hlm.31)

Penggambaran yang lebih nyata tentang perempuan sebagai objek seksual bagi laki-laki, seperti dalam kutipan:

[...] adalah wanita sintal dengan pinggul padat dalam remasan serakan potongan rambut[...] ("Tajen Terakhir", hlm. 21).

Memang dari semua teks yang dikaji dalam artikel ini tidak seluruhnya menghadirkan perempuan dalam dunia tajen. Namun dari tiga teks ("Tuung Kuning", "Tajen", dan "Tajen Terakhir") dapat dipelajari praktik ideologi patriarkhi dalam dunia tajen. Dalam dunia ini, harga perempuan Bali sangat rendah, tidak hanya di bawah kuasa laki-laki sendiri, sekalipun bebotoh tetapi lebih rendah dari ayam jago. Bisa memberi keturunan kepada suami 
tidak cukup memberi perempuan Bali kehormatan tetapi harus memberi anak laki-laki. Karena itu, perempuan Bali yang tidak bisa memberi keturunan semakin tidak dihargai, seperti diceritakan dalam cerpen "Tajen". Posisi rendah perempuan Bali dalam dunia tajen tampak pada pandangan laki-laki yang melihat perempuan sebagai objek seksual. Hal ini memang tidak tampak dalam cerita "Tuung Kuning," tetapi sangat kuat dalam cerpen "Tajen" dan “Tajen Terakhir."

\section{Simpulan}

Berbicara mengenai tajen, berbicara mengenai sebuah dunia yang merupakan permainan kegemaran laki-laki Bali. Dunia ini terbangun oleh sejumlah aspek, seperti ayam jago dengan status lebih tinggi ketimbang anak perempuan dan istri, taruhan, dan obsesi kemenangan. Di dalam tajen, sebagaimana semua dunia kultural Bali, perempuan hadir di bawah kuasa laki-laki dan menjalani takdir tragis adat. Hasil kajian ini menunjukkan, perspektif ideologi patriarkhi tampaknya cukup memadai untuk memahami nasib tragis perempuan dalam dunia tajen. Konsep "status kebinatangan", "kanibalisme", "pemujaan kuasa-kuasa roh haus korban darah segar" dalam memahami nasib tragis perempuan dalam dunia tajen, melampaui tuduhan terhadap ideologi patriarkhi, masih harus dikaji lebih lanjut. Konsep tersebut menjelaskan, ada kuasa lain lebih tinggi daripada ideologi patriarkhi, sebagai pengendali tindakan manusia, yaitu "status kebinatangan", "kanibalisme", "pemujaan kuasa-kuasa roh haus korban darah segar". Persoalan pokok kedua cerpen "Tajen" dan "Tajen Terakhir", obsesi kemenangan seperti candu. Obsesi ini menggerakkan seorang bebotoh menjalani dinamika dunia tajen, legitimasi praktik kultural menomorduakan cinta, keluarga, istri; memposisikan ayam jago di atas istri dan anak perempuan, mengorbankan harta demi kesenangan sendiri atas nama kuasa laki-laki.

\section{Ucapan terima kasih}

Selama proses penelitian ini, penulis melakukan sejumlah diskusi dengan beberapa sastrawan Bali, seperti Cok Sawitri, Oka Rusmini, dan I Made Adnyana Ole tentang cerita seputar tajen. Dosen sekaligus perupa Hardiman juga telah memberi wawasan yang 
sangat penting, bagaimana seorang seniman memilih tema di dalam kehidupan ini. Kepada para sastrawan dan seniman, saya menyampaikan terima kasih atas informasinya.

\section{Daftar pustaka}

Atmadja, Nengah Bawa, Anantawikrama, dan Ariyani, Luh Putu Sri. 2015. Tajen di Bali, Perspektif Homo Complexus. Denpasar: Pustaka Larasan.

Baraas, Faisal. 1982. “Tajen” dalam Leak. Jakarta: Balai Pustaka. Hlm.2933.

Barry, Peter. 2010. Beginning Theory: Pengantar Komprehensif Teori Sastra dan Budaya (Harviyah Widyawati dan Evy S. penerjemah). Yogyakarta: Jalasutra.

Brannigan, John. 1999. New Historicism and Cultural Materialism. New York: St. Martin's Press.

Bressler, Charles E., 2007. Literary Cristicism: An Introduction to Theory and Practice (Fourth Edition). New Jersey: Pearson Prentice Hall.

Geertz, Clifford. 1996. Tafsir Kebudayaan (Francisco Budi Hardiman penerjemah). Yogyakarta: Kanisius.

Greenblatt, Stephen. 1980. Renaissance Self-Fashioning: from More to Shakespeare. Chicago: University of Chicago Press.

Greenblatt, Stephen. 1983. "The Form of Power and the Form of Power in the Renaissance", Genre 15. Hal. 3-6.

Greenblatt, Stephen. 2005. "Towards a Poetics of Culture". Dalam Payne, Michael (ed). The Greenblatt Reader. Victoria: Blackwell. Hal. 18-29.

Liu, Hong. 2011. "Lalu lintas Budaya antara Cina dan Indonesia 19491965." Dalam Lindsay, Jennifer dan Liem Maya H.T. (eds). Ahli Waris Budaya Dunia, Menjadi Indonesia 1950-1965. Denpasar: Pustaka Larasan dan KITLV Jakarta. Hlm. 145-168.

Putra, I Nyoman Darma. 2011. A Literary Mirror; Balinese reflections on modernity and identity in the twentieth century. Leiden: KITLV/ Brill.

Setia, Putu. 1986. Menggungat Bali. Jakarta: Grafiti.

Silverman, David. Interpreting Qualitative Data, Methods for Analysing Talk, Text and Interaction. London, New Delhi: SAGE 
Publications.

Soethama, Gede Aryantha. 2016. "Tajen terakhir" dalam Cerpen Pilihan Kompas 2016, Anak ini Ingin Mengencingi Jakarta. Jakarta: Buku Kompas.

Widdowson, Peter and Selden, Raman. 1993. A Reader's Guide to Contemporary Literary Theory. Great Britain: The University Press of Kentucky.

\section{Lontar}

Pengayam ayam, koleksi Gedong Kirtya Singaraja

\section{Cerita Rakyat Bali}
1. I Bagus Diarsa
2. Manik Angkeran
3. Tuung Kuning
4. I Kenengneng 